\title{
Suitability of Palm wine as a Multi Functional Beverage
}

Created by: Pogueri Nwaiwu

Revised by: Paul Chikezie

Version received: 31 January 2020

The reference to palm wine as a drink with many functionalities has increased over the years. However, few empirical tests have been carried out on humans to substantiate the claims. This perspective looks at the biochemical and microbiological reports on palm wine to highlight the constituents that are associated with functional beverages. Based on the constituents of the drink, it may qualify as a multifunctional beverage because several investigators have demonstrated disease risk reduction, improved nutrition and health outcomes in many studies, albeit in rats rather than humans. The constituents found in functional beverages are present in the drink. However, when assessed under European Union regulations, fermented palm wine (from 3\% alcohol) cannot be regarded as a functional beverage because beverages that contain over $1.2 \%$ alcohol cannot be approved for any claim on health or nutritional benefit. The fresh sap with much lower alcohol may be suitable after it is refined and subjected to scientific examination to determine quantities of the drink that can confer health benefits on humans.

\subsection{Introduction}

Palm wine is a milky white sugary beverage obtained from the sap of different palm tree species. Millions of people in Asia and sub-Saharan Africa consume it and it features prominently in the socioeconomic life of many communities. In south-eastern Nigeria, it is used in traditional marriages [1] and the special moment guests and well-wishers look forward to, is when the bride presents a cup of palm wine to the groom to drink and signify that her search for a husband has ended. The drink is now a commercial success and can be found in cans or glass bottles that are marketed locally and internationally. The oenological potentials of the drink have been reviewed [2] and it was highlighted that the drink has many constituents of commercial or traditional red and white wines (e.g Merlot and Shiraz). In that report, the drink was proposed to have the potential of being turned into a vintage drink if current methods of production used in commercial wines are applied. Furthermore, the huge possibilities of biotechnological application or genetic manipulations to obtain new flavours from the drink was pointed out.

Many health benefits have been attributed to the drink. It has been reported to have low alcoholic content, contains yeasts, lactic acid, and acetic acid which confers probiotic qualities to the drink. It is believed to contain several beneficial chemicals and it is regarded as an antioxidant. From the aforementioned attributes, anecdotal debates suggest that palm wine is a wonder drink and could qualify as a beverage that can mitigate the undesirable effects of many ailments. Food is functional when it shows positive physiological effects due to its nutraceutical content [3]. In addition, foods (including beverages) are regarded as functional if it beneficially affects the functions in the body in a way that improves the state of health and well-being, or reduction of risk of disease[4]. The regulatory framework in Europe imposes huge requirements on food operators and claims for functional foods can be for nutritional, health or reduction of disease risk[5]. In many places where palm wine is consumed, there is poor government regulation. In general, beverages are the most active functional food category but there are specific concerns over their safety[6]. Here, the suitability of palm wine as a functional beverage was explored by the examination of previous reports to ascertain if there is a link between constituents of the drink and functionality.

\subsection{Beneficial microorganisms found in palm wine}


The occurrence of yeasts, acetic acid bacteria and lactic acid bacteria (LAB) is widely reported in palm wine. Species from these groups of microorganisms are recognized as functional microorganisms because they can stimulate probiotic functions, and fortify food or beverage with some health-promoting bioactive compounds[7].

\subsection{Yeasts}

Many studies have demonstrated additional benefits of yeasts as valuable sources of amino acids and peptides [8] [9], which can be used in functional foods and dietary supplements. Saccharomyces boulardii yeast strain has been extensively studied for its probiotic effects and it was found that the clinical activity of $S$. boulardii is especially relevant to antibiotic-associated diarrhoea and recurrent Clostridium difficile intestinal infections. Palm wine contains yeasts especially S. cerevisiae [10] at all stages of fermentation. Other yeasts include Pichia and Candida [11]. It is believed that the dregs or sediments that form when a bottle of palm wine is left standing contains a rich suspension of yeasts.

\subsection{Acetic acid bacteria}

Acetic acid bacteria are widespread and play an important role in the production of food and beverages [12] [13] by oxidizing ethanol to acetic acid (vinegar). This is why they are mainly found in the latter part of palm wine fermentation when there is enough ethanol to oxidize. Acetic acid from apples [14] is believed to have many health benefits. It includes inhibition of growth of harmful bacteria, enables lower blood sugar levels and diabetes control, weight loss, cholesterol reduction, and may have protective effects against cancer. It would be interesting to compare the acetic acid from palm wine and the one obtained from apples to ascertain the source with the best impact on health.

\subsection{Lactic acid bacteria}

Lactic acid bacteria are responsible for the malolactic fermentation, which follows the alcoholic fermentation by yeasts [16]. The organism is considered a cell factory for the delivery of functional biomolecules and ingredients [17]. Its link with greater longevity and improved health is the basis for using lactobacilli in many probiotic products today [18]. During the initial part of palm wine fermentation, lactic acid is produced but its concentration is generally less than that of ethanol or acetic acid. Bacteriocin producing LAB found in palm wine includes Lactobacillus species. These species can inhibit the growth of Listeria monocytogenes, a foodborne pathogen that can cause listeriosis in the elderly, neonates, immune-compromised persons and pregnant women [19]. The probiotic effect of lactic acid produced during palm wine fermentation is unknown.

\subsection{Antioxidant properties, biochemical composition, and effect on rats}

\subsection{Antioxidant properties}

Antioxidants like vitamins $\mathrm{C}$ and polyphenols are molecules that counteract free radicals and prevent the damage caused by them [20][21]. Beverages and foods rich in antioxidants include tea[22], coffee [23], wine[24][25] and fruits and vegetables[26]. Palm wine contains natural phenols [10] and in vitro tests have shown antioxidant activity[27]. Natural phenols have beneficial properties [28]and possess antifungal, antiviral and anti-bacterial attributes[29]. The characteristics of specific phenols from palm wine are unknown and need further studies. However, it's efficacy as a good antioxidant may be because it contains natural antioxidants like vitamin C. Contrastingly, a study [30] found that palm wine depletes the body's antioxidants, which may allow free radicals to attack and subject the body to a state of oxidative stress.

\subsection{Biochemical composition}


The biochemical composition of palm saps vary among different locations and may depend on the species of a palm tree from which the palm wine was sourced. The biochemical makeup of palm wine has been reported [31], and it consists of different sugars. This ranged between 0.10 of maltose and $8.74 \mathrm{mg} / 100 \mathrm{ml}$ of sucrose. Other values reported include protein $(39.03 \mathrm{mg} / 100 \mathrm{ml})$, free amino acids $(59.63 \mathrm{mg} / 100 \mathrm{ml})$, lipids $(62.65 \mathrm{mg} / 100 \mathrm{ml})$, and ethanol $(3.4 / 100 \mathrm{ml})$. Essential elements like magnesium, zinc, and phosphorus, which are normally part of a healthy diet, were found present in the drink. In another biochemical characterization [32], the initial pH, reducing sugars and ethanol contents were found to be $5.23 \pm 0.18,45.55 \pm 4 \mathrm{~g} / \mathrm{L}$ and $0.08 \% \pm 0.02 \%$ respectively. Evaluation of Elaeis and Raphia species palm wine from trade showed that samples had a pH of less than 5.0 and contained 5.9-11.6, 2.2-7.1, 4.2-43.0, and 4.4-43.7 g/L of acetic acid, lactic acid, ethanol, and glucose, respectively [10]. Other metabolites analysed varied between the two palm wine species.

\subsection{Effect of palm wine on rats}

At present, there are more studies on the beneficial effects of palm wine on rats rather than humans. Although using rats is an ideal starting point, more studies on humans are required to establish if the effects seen in rats can manifest in humans. Studies on rats indicate both beneficial and harmful effects of palm wine. The drink has been shown to modulate glucose homeostasis by enhancing insulin secretion and inhibiting redox imbalance in a rat diabetes model [33]. It has also been suggested that palm wine extenuates redox imbalance and modulates activities of glycolytic and cholinergic enzymes in hyperglycaemia-induced testicular injury in type 2 diabetic rats [34]. Another study found that that regular intake of palm wine may not significantly affect body weight nor testis weight, but can gradually distort testicular tissue architecture with abnormally structured cells in rats [35].

\subsection{Health Concerns about palm wine}

\subsection{Obesity and Diabetes}

Due to its sugary nature, palm wine may not be suitable for regular consumption by people that are obese or those living with diabetes. The sugar content is highest when the drink is freshly harvested but decreases as fermentation progresses. It would be helpful if commercial producers of the drink can indicate the quantity and specific type of sugar in the processed product's label to enable consumers to make informed decisions on the quantity to consume in order not to exacerbate any underlying adverse condition.

\subsection{Alcohol}

The ethanol content of palm wine varies. The fresh sap is reported to be less than two per cent but it increases up to $5 \%$ when it ferments. If an assessment under European Union regulations is carried out on fermented palm wine (from 3\% alcohol), it would not pass the assessment. It would not be regarded as a functional beverage because beverages that contain over $1.2 \%$ alcohol cannot claim any health or nutritional benefit[36]. Ethanol consumption in large amounts can harm the liver and cause many complications in the body. In Nigeria where millions of people consume palm wine, there are fears that consumption by new mothers may harm neonates because some mothers consume the drink postpartum to increase the flow of breast milk[37]. Those that practice this for increased lactation believe that it is harmless since it is the low-ethanol fresh palm wine that is consumed. However, it has been argued that palm wine consumption post-partum is a myth with no scientific basis or benefit and a harmful practice[38].

\subsection{Extraneous contaminants}

The biggest health concern in palm wine consumption comes from intentional and unintentional contamination of the drink with extraneous materials, which are harmful to the human body. In communities with an abundance of palm trees, there is a steady supply of palm wine and little 
adulteration occurs. However, in places where the drink is scarce, it is common knowledge that some palm wine sellers try to boost yield by adding water to the drink and then supplement with artificial sweeteners to maintain the sugary taste. Unintentional contamination that occurs during processing has been summarized in a review[39], and it was emphasized that chemical contaminants associated with palm wine are potential food safety hazards. It was recommended that a detailed hazard analysis that covers palm wine processing and the supply chain would be beneficial to public health. More regulatory oversight was also suggested. Regulation for private consumption may be difficult to enforce hence it would be beneficial to enforce food safety standards on entrepreneurs that sell to the public. Presently the drink is sold in restaurants, roadside kiosks, and shacks. In many communities, the product is sold under a tree with a few benches and tables. Regulatory enforcement should cover all categories of sellers, no matter how small to help safeguard public health.

\subsection{Insect contamination and link with Nipah virus}

After harvesting of palm wine, it is not uncommon to see dead flies or bees floating in the receptacle that was hung on the palm tree to collect the palm sap. There are concerns that pathogens on the dead insects, which may be harmful to humans may get into the palm wine. Other animals may also try to gain access to the palm wine during tapping. Most prominent is the case of Nipah viral disease, first reported in Malaysia in 1998. It is a zoonotic infection caused by Nipah virus, a paramyxovirus biosafety level-4 pathogen, belonging to the genus Henipavirus of the family Paramyxoviridae [40][41][42]. Transmission to humans from the vector Pteropus spp, a fruit bat which harbours the virus has been demonstrated and fatalities in some Asian countries have been reported[43]. During tapping of palm wine, it was found that the bat invades the palm wine receptacle on the tree to drink and pass excreta into the drink. Preventive control is the use of mesh and appropriate coverage to ensure insects and bats do not have access to the palm wine before, during or after tapping.

\section{Conclusions}

Most of the investigations that show that palm wine is efficient in reducing disease risk have been performed on rats and not humans. In addition, there are hardly any properly controlled study on humans to demonstrate the nutritional benefit of the drink. Furthermore, there is no consistency in the literature on the concentration of the drink that is beneficial. This may be because the water abundance of the drink varies from location to location and so the actual concentration of palm wine that will facilitate functional benefits is unknown. From currently available data, the evidence that supports palm wine as a multifunctional beverage in humans is weak and needs further research. However, microorganisms and chemical elements and compounds that support nutritional, health and reduction of disease risk in well-known functional foods and beverages are present in palm wine.

\section{References}

1. Ogueri Nwaiwu; Use of Fragments from D1/D2 Domain of 26S rRNA Gene to Select Saccharomyces cerevisiae from Palm Wine. Journal of Applied Life Sciences Internationa/ 2016, 5, 1-5, 10.9734/jalsi/2016/26373.

2. Ogueri Nwaiwu; Martin Itumoh; Molecular Phylogeny of Yeasts from Palm Wine and Enological Potentials of the Drink. Annual Research \& Review in Biology 2017, 20, 1-12, 10.9734/ARRB/2017/37748.

3. Dey G., Sireswar S. . Emerging Functional Beverages: Fruit Wines and Transgenic Wines Alcoholic Beverages; International Life Sciences Institute: Washington, DC, United States, 2002; pp. 471-514.

4. Ellen H.M. Moors; Functional foods: regulation and innovations in the EU.Innovation: The European Journal of Social Science Research 2012, 25, 424-440, 10.1080/13511610.2012.726407.

5. Maria Rosaria Corbo; Antonio Bevilacqua; Leonardo Petruzzi; Francesco Pio Casanova; Milena Sinigaglia; Functional Beverages: The Emerging Side of Functional Foods. Comprehensive Reviews in Food Science and Food Safety 2014, 13, 1192-1206, 10.1111/1541-4337.12109.

6. Jyoti P. Tamang; Dong-Hwa Shin; Su-Jin Jung; Soo-Wan Chae; Functional Properties of Microorganisms in Fermented Foods. Frontiers in Microbiology 2016, 7, 6358, 10.3389/fmicb.2016.00578. 
7. Rita Rakowska; Anna Sadowska; Ewa Dybkowska; Franciszek Świderski; Spent yeast as natural source of functional food additives. Roczniki Państwowego Zakładu Higieny 2017, 68, 115-121, 0.

8. C.O. Ibegbulem; C.U. Igwe; G.N. Okwu; C.O. Ujowundu; E.N. Onyeike; E.O. Ayalogu; Total amino acid profiles of heatprocessed fresh Elaeis guineensis and Raphia hookeri wines. Food Chemistry 2013, 138, 1616-1620, 10.1016/j.foodchem.2012.11.110.

9. Why Is Nutritional Yeast Good for You?. Health line. Retrieved 2019-10-28

10. Ogueri Nwaiwu; Vincent I. Ibekwe; Ekperechi S. Amadi; Angela C. Udebuani; Ferdinand C. Nwanebu; Okechukwu I. Oguoma; Justin C. Nnokwe; Evaluation of Fermentation Products of Palm Wine Yeasts and Role of Sacoglottis gabonensis Supplement on Products Abundance. Beverages 2016, 2, 9, 10.3390/beverages2020009.

11. Eliane Barbosa Evanovich Dos Santos; Phylogenetics. Recent Advances in Phylogenetics 2019, 0, 25-42, 10.5772/intechopen.79422.

12. Rodrigo José Gomes; Maria De Fátima Borges; Morsyleide De Freitas Rosa; Raúl Jorge Hernan Castro-Gómez; Wilma Aparecida Spinosa; Acetic Acid Bacteria in the Food Industry: Systematics, Characteristics and Applications. Food technology and biotechnology 2018, 56, 139-151, 10.17113/ftb.56.02.18.5593.

13. Jonas De Roos; Luc De Vuyst; Acetic acid bacteria in fermented foods and beveragesCurrent Opinion in Biotechnology 2018, 49, 115-119, 10.1016/j.copbio.2017.08.007.

14. 6 Health Benefits of Apple Cider Vinegar, Backed by Science. Health line. Retrieved 2019-10-28

15. Aline Lonvaud-Funel. Lactic acid bacteria in the quality improvement and depreciation of wine; Springer, Dordrecht: Berlin, Germany, 0; pp. 317-331.

16. Deborah M. Waters; Alexander Mauch; Aidan Coffey; Elke K. Arendt; Emanuele Zannini; Lactic Acid Bacteria as a Cell Factory for the Delivery of Functional Biomolecules and Ingredients in Cereal-Based Beverages: A Review. Critical Reviews in Food Science and Nutrition 2014, 55, 503-520, 10.1080/10408398.2012.660251.

17. Elisa Salvetti; Paul W. O'Toole; The Genomic Basis of Lactobacilli as Health-Promoting Organisms.Bugs as Drugs 2018, 5, 49-71, 10.1128/microbiolspec.bad-0011-2016.

18. Bertrand Tatsinkou Fossi; Ndjouenkeu R; Tongwa M; Cho-Ngwa F; Goghomu S Tatsinkou Fossi B; Screening for Bacteriocins Producing Probiotic Bacteria from Fermented Sap of Palm Trees (Elaeis Guineesis and Raffia Sudanica): Production and Partial Characterization of Bacteriocins. Journal of Applied Biotechnology \& Bioengineering 2017, 2, 1-8, 10.15406/jabb.2017.02.00017.

19. Nwaiwu, O.; An overview of Listeria species in Nigeria.International Food Research Journal 2015, 22, 455-464, 1.

20. Jorge Hoyos-Arbeláez; Mario Vázquez; José Contreras-Calderón; Electrochemical methods as a tool for determining the antioxidant capacity of food and beverages: A review. Food Chemistry 2017, 221, 1371-1381, 10.1016/j.foodchem.2016.11.017.

21. D. Venkat Ratnam; D.D. Ankola; V. Bhardwaj; D.K. Sahana; M.N.V. Ravi Kumar; Role of antioxidants in prophylaxis and therapy: A pharmaceutical perspective. Journal of Controlled Release 2006, 113, 189-207, 10.1016/j.jconrel.2006.04.015.

22. Corina Serban; Amirhossein Sahebkar; Diana Simona Antal; Sorin Ursoniu; Maciej Banach; Effects of supplementation with green tea catechins on plasma C-reactive protein concentrations: A systematic review and meta-analysis of randomized controlled trials. Nutrition 2015, 31, 1061-1071, 10.1016/j.nut.2015.02.004.

23. Gian Tenore; Maria Daglia; Valentina Orlando; Emanuela D'Urso; Seyed Saadat; Ettore Novellino; Seyed Nabavi; Coffee and Depression: A Short Review of Literature. Current Pharmaceutical Design 2015, 21, 5034-5040, 10.2174/1381612821666150825145112.

24. Giovanna Giovinazzo; Francesco Grieco; Functional Properties of Grape and Wine Polyphenols.Plant Foods for Human Nutrition 2015, 70, 454-462, 10.1007/s11130-015-0518-1.

25. Ana Artero; Arturo Artero; Juan J. Tarín; Antonio Cano; The impact of moderate wine consumption on health. Maturitas 2015, 80, 3-13, 10.1016/j.maturitas.2014.09.007.

26. Anna R. Proteggente; Ananth Sekher Pannala; George Paganga; Leo Van Buren; Eveline Wagner; Sheila Wiseman; Frans Van De Put; Clive Dacombe; Catherine A. Rice-Evans; The antioxidant activity of regularly consumed fruit and vegetables reflects their phenolic and vitamin C composition.. Free Radical Research 2002, 36, 217-233, 10.1080/10715760290006484.

27. HA Oboh, EO Okhai; Antioxidant and Free Radical Scavenging Abilities of some Indigenous Nigerian DrinksNigerian Journal of Basic and Applied Sciences 2012, 20, 21-26.29, 3.

28. Massimo Stefani; Stefania Rigacci; Beneficial properties of natural phenols: Highlight on protection against pathological conditions associated with amyloid aggregation. BioFactors 2014, 40, 482-493, 10.1002/biof.1171.

29. Mendel Friedman; Antibacterial, Antiviral, and Antifungal Properties of Wines and Winery Byproducts in Relation to Their Flavonoid Content. Journal of Agricultural and Food Chemistry 2014, 62, 6025-6042, 10.1021/jf501266s.

30. P S Ogunro; P O Ologunagba; The effect of palm wine on lipid peroxidation and antioxidant status of rural dwellers in South West Nigeria.. Nigerian Postgraduate Medical Journal 2011, 18, 186-190, 4. 
31. I. E. Ezeagu; M. A. Fafunso; F. E. Ejezie; Biochemical constituents of palmwine.Ecology of Food and Nutrition $\mathbf{2 0 0 3 ,}$ 42, 213-222, 10.1080/03670240390226222.

32. Detto Karamoko; N'Dédé Théodore Deni; Jean-Luc Aboya Moroh; Koffi Maïzan Jean-Paul Bouatenin; Koffi Marcellin Dje; Biochemical and Microbial Properties of Palm Wine: Effect of Tapping Length and Varietal Differences. Food and Nutrition Sciences 2016, 7, 763-771, 10.4236/fns.2016.79077.

33. Ochuko L. Erukainure; Olajumoke A. Oyebode; Omamuyovwi M. Ijomone; Chika I. Chukwuma; Neil A. Koorbanally; Md. Shahidul Islam; Raffia palm (Raphia hookeri G. Mann \& H. Wendl) wine modulates glucose homeostasis by enhancing insulin secretion and inhibiting redox imbalance in a rat model of diabetes induced by high fructose diet and streptozotocin.. Journal of Ethnopharmacology 2019, 237, 159-170, 10.1016/j.jep.2019.03.039.

34. Ochuko L. Erukainure; Rebecca Reddy; Md. Shahidul Islam; Raffia palm (Raphia hookeri ) wine extenuates redox imbalance and modulates activities of glycolytic and cholinergic enzymes in hyperglycemia-induced testicular injury in type 2 diabetic rats. Journal of Food Biochemistry 2019, 43, e12764, 10.1111/jfbc.12764.

35. Ubi Essien Isaac, Frank Chinedu Akpuaka, Godwin Unukpai Ndukwe; The effect of intake of palm wine on body weight and testicular microarchitecture in adult wistar rats. Journal of Experimental and Clinical Anatomy 2017, 16, 12-17, 4.

36. Regulation (EC) No 1924/2006 of the European parliament and of the council on nutrition and health claims made on foods

37. Osarolube E, Nwaiwu O; Probing Yeast Fermented Palm Wine Interactions with the Surface of its Plastic Container. Archives of Applied Science Research 2016, 8, 77-84, 5.

38. Palm wine is harmful to new mum and a breastfeeding child. Adesanya's blog. Retrieved 2019-10-28

39. Ogueri Nwaiwu; Martin Itumoh; Chemical Contaminants Associated with Palm Wine from Nigeria Are Potential Food Safety Hazards. Beverages 2017, 3, 16, 10.3390/beverages3010016.

40. M. Saiful Islam; Hossain M.S. Sazzad; Syed Moinuddin Satter; Sharmin Sultana; M. Jahangir Hossain; Murshid Hasan; Mahmudur Rahman; Shelley Campbell; Deborah L. Cannon; Ute Ströher; et al.Peter DaszakStephen P. LubyEmily S. Gurley Nipah Virus Transmission from Bats to Humans Associated with Drinking Traditional Liquor Made from Date Palm Sap, Bangladesh, 2011-2014. Emerging Infectious Diseases 2016, 22, 664-670, 10.3201/eid2204.151747.

41. Stephen P. Luby; The pandemic potential of Nipah virus.Antiviral Research 2013, 100, 38-43, 10.1016/j.antiviral.2013.07.011.

42. Vikrant Sharma; Sulochana Kaushik; Ramesh Kumar; Jaya Parkash Yadav; Samander Kaushik; Emerging trends of Nipah virus: A review. Reviews in Medical Virology 2018, 29, e2010, 10.1002/rmv.2010.

43. Raj Kumar Singh; Kuldeep Dhama; Sandip Chakraborty; Ruchi Tiwari; Senthilkumar Natesan; Rekha Khandia; Ashok Munjal; Kranti Suresh Vora; Shyma K. Latheef; Kumaragurubaran Karthik; et al.Yashpal Singh MalikRajendra SinghWanpen ChaicumpaDevendra T. Mourya Nipah virus: epidemiology, pathology, immunobiology and advances in diagnosis, vaccine designing and control strategies - a comprehensive review. Veterinary Quarterly 2019, 39, 26-55, 10.1080/01652176.2019.1580827.

\section{Keywords}

Palm wine; functional beverage; yeasts; food safety; acetic acid; lactic acid; sugar; antioxidant (c) 2020 by the author(s). Distribute under a Creative Commans CC BY license 